\title{
Non-invasive Oxygen Strategies to Manage Confirmed COVID-19 Patients in Indian Intensive Care Units: A Survey
}

\author{
Ashwin Subramaniam ${ }^{1}$, Jumana Y Haji ${ }^{2}$, Prashant Kumar ${ }^{3}$, Kollengode Ramanathan ${ }^{4}$, Arvind Rajamani ${ }^{5}$
}

\begin{abstract}
Background: About 5\% of hospitalized coronavirus disease 2019 (COVID-19) patients will need intensive care unit (ICU) admission for hypoxemic respiratory failure requiring oxygen support. The choice between early mechanical ventilation and noninvasive oxygen therapies, such as, highflow nasal oxygen (HFNO) and/or noninvasive positive-pressure ventilation (NPPV) has to balance the contradictory priorities of protecting healthcare workers by minimizing aerosol-generation and optimizing resource management. This survey over two timeframes aimed to explore the controversial issue of location and noninvasive oxygen therapy in non-intubated ICU patients using a clinical vignette.

Materials and methods: An online survey was designed, piloted, and distributed electronically to Indian intensivists/anesthetists, from Private Hospitals, Government Hospitals, and Medical College Hospitals (the latter two referred to as first-responder hospitals), who are directly responsible for admitting/managing patients in ICU.

Results: Of the 204 responses (125/481 in phase 1 and 79/320 in phase 2), 183 responses were included. Respondents from first-responder hospitals were more willing to manage non-intubated hypoxemic patients in neutral pressure rooms, while respondents from private hospitals preferred negative-pressure rooms $(p<0.001)$. In both the phases, private hospital doctors were less comfortable to use any form of noninvasive oxygen therapies in neutral-pressure rooms compared to first-responder hospitals (low-flow oxygen therapy: 72 vs $50 \%, p<0.01$; HFNO: 47 vs $24 \%, p<0.01$ and NPPV: 38 vs $28 \%, p=0.20$ ).

Interpretation:Variations existed in practices among first-responder and private intensivists/anesthetists. The resource optimal private hospital intensivists/anesthetists were less comfortable using noninvasive oxygen therapies in managing COVID-19 patients. This may reflect differential resource availability necessitating resolution at national, state, and local levels.

Keywords: Conservative oxygen therapy, COVID-19, High flow nasal cannula oxygen therapy, Hypoxemia, Indian intensive care unit, Low flow nasal oxygen, NIV: Noninvasive mechanical ventilation, SARS-COV-2.

Indian Journal of Critical Care Medicine (2020): 10.5005/jp-journals-10071-23640
\end{abstract}

\section{INTRODUCTION}

About 5\% of hospitalized coronavirus disease 2019 (COVID-19) patients need intensive care unit (ICU) admission for hypoxemic respiratory failure. ${ }^{1,2}$ Before the COVID-19 pandemic, noninvasive oxygen therapies, such as, high-flow nasal oxygen (HFNO) and/or noninvasive positive-pressure ventilation (NPPV), were increasingly used in hypoxemic patients due to their proven benefits on minimizing the need for endotracheal intubation. ${ }^{3}$ However, HFNO/NPPV has been avoided in the early phase of the COVID-19 pandemic due to concerns of their aerosol-generation, ${ }^{4}$ potentially increasing healthcare worker (HCW) infections. The consequent high rates of endotracheal intubation caused rapid depletion of ICU resources and potentially increased mortality. ${ }^{5}$

However, new research shows that HFNO may not be as aerosol-generating as initially thought..$^{6-10}$ Moreover, COVID-19 management guidelines give contrary statements on its use. ${ }^{11-13}$ Therefore, the choice between early mechanical ventilation and HFNO/NPPV has to balance the contradictory priorities of protecting HCWs by minimizing aerosol-generation vs optimizing resource management. This may be particularly difficult in India, which has low numbers of ventilator beds and intensivists per capita, ${ }^{14,15}$ and has already seen high numbers of HCWs infections even before the surge. ${ }^{16,17}$

There is no literature on the oxygen-therapy practices for nonintubated COVID-19 patients used by critical care physicians in India. Hence, we surveyed Indian intensivists, over two timeframes, to systematically explore this issue.
${ }^{1}$ Department of Intensive Care, Frankston Hospital, Frankston, VIC Monash University, VIC, Frankston, Australia

${ }^{2}$ Department of Anesthesia and Critical Care, Aster CMI Hospital, Bengaluru, Karnataka, India

${ }^{3}$ Department of Critical Care Medicine, Kailash Hospital Neuro Institute KHNI, Noida, Uttar Pradesh, India

${ }^{4}$ Department of Critical Care, National University Hospital, Singapore

${ }^{5}$ Department of Intensive Care, University of Sydney, Nepean Clinical School and Nepean Hospital, Kingswood, New South Wales, Australia

Corresponding Author: Jumana Y Haji, Department of Anesthesia and Critical Care, Aster CMI Hospital, Bengaluru, Karnataka, India, Phone: +919686521100, e-mail: drjyhaji@gmail.com

How to cite this article: Subramaniam A, Haji JY, Kumar P, Ramanathan K, Rajamani A. Non-invasive Oxygen Strategies to Manage Confirmed COVID-19 Patients in Indian Intensive Care Units: A Survey. Indian J Crit Care Med 2020;24(10):926-931.

Source of support: Nil

Conflict of interest: None

\section{Materials and Methods}

The detailed methodology of the survey is published elsewhere. ${ }^{18,19}$ The survey was distributed to HCWs from Private Hospitals, Government Hospitals, and Medical College Hospitals in two phases_Phase 1 between 25/03/2020 and 06/04/2020 and phase

() The Author(s). 2020 Open Access This article is distributed under the terms of the Creative Commons Attribution 4.0 International License (https://creativecommons. org/licenses/by-nc/4.0/), which permits unrestricted use, distribution, and non-commercial reproduction in any medium, provided you give appropriate credit to the original author(s) and the source, provide a link to the Creative Commons license, and indicate if changes were made. The Creative Commons Public Domain Dedication waiver (http://creativecommons.org/publicdomain/zero/1.0/) applies to the data made available in this article, unless otherwise stated. 
2 between 20/04/20 and 30/04/20. As this manuscript primarily deals with clinical management issues, we only included the responses from intensivists/anesthetists with direct responsibility of admitting/managing patients in ICU. To explore their approach to noninvasive oxygen therapy in non-intubated ICU patients, we presented a case vignette of a hypoxemic COVID-19 patient who was not sick enough to require invasive mechanical ventilation and sought a response on the proposed modality and location of treatment (SupplementaryFig. 1). The Government Hospitals and Medical College Hospitals were designated as first-responders by the Ministry of Health. ${ }^{20}$ The responses from first-responder hospitals were compared with the responses from private hospitals. Categorical data are reported as percentages of valid responses and comparative analysis of responses between the two phases using Fisher's exact test with a two-tailed alpha-error of $5 \%$ ( $p<$ $0.05)$ using SPSS $^{\mathrm{TM}} \mathrm{v} .26$.

\section{Results}

In total, 204 responses were received (25\% response rate), with $125 / 481$ in phase $1(26 \%)$ and 79/320 (25\%). Respondents comprised of intensivists (82\%), anesthetists ( $8 \%)$, ICU nurses (8\%), and emergency HCWs (2\%). For the final analysis, 183 responses from intensivists/anesthetists were included. Most respondents were from Private Hospitals ( $n=137 ; 75 \%$ ). The remainder were from Government Hospitals ( $n=23 ; 12 \%)$ and Medical Colleges $(n=$ 24; 13\%). There were interstate variations (Supplementary Fig. 2).

More than $60 \%$ of respondents did not prefer a neutral-pressure room in managing the non-intubated hypoxemic COVID-19 patient in the clinical vignette (Fig. 1). Respondents from first-responder hospitals were more willing to manage such patients in neutral pressure rooms, while respondents from private hospitals preferred negative-pressure rooms $(p<0.001)$. There was a significant increase in the proportion of private hospital intensivists/anesthetists who reported that they would not use any form of noninvasive oxygen therapy for COVID-19 patients (7\% in phase 1 vs $24 \%$ in phase $2 ; p$ $<0.001)$. Significantly more respondents reported that they would not use HFNO (24 vs 31\%; $p=0.02)$ and NPPV $(41-46 \% ; p=0.70)$ in phase 2 compared to phase 1.

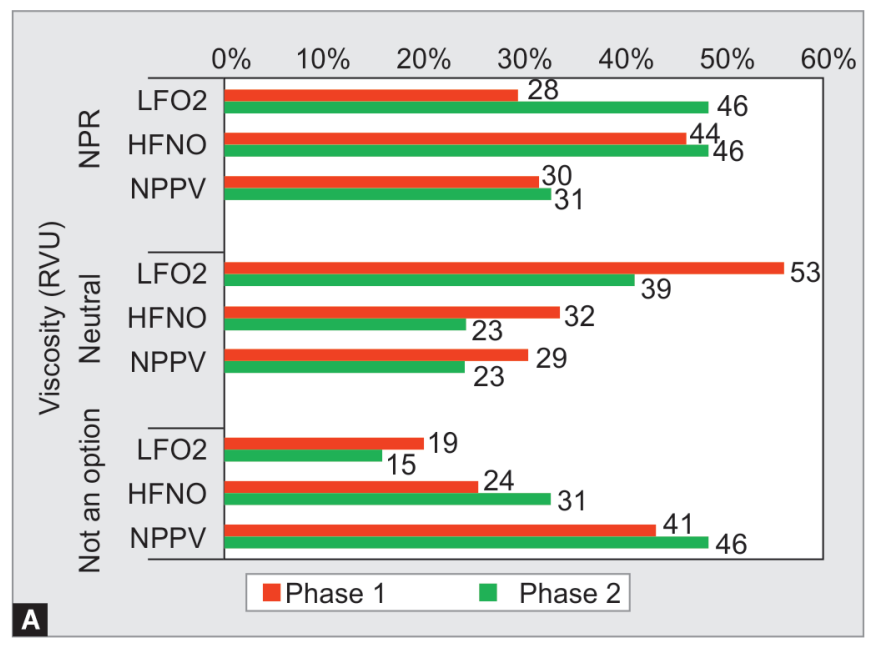

When specifically explored about oxygen therapies, significant variations emerged between phases 1 and 2 for all forms of noninvasive oxygen therapies (Fig. 2). In both the phases, private hospital intensivists/anesthetists were less comfortable to use any form of noninvasive oxygen therapies in neutral-pressure rooms compared to first-responder hospitals $\left(\mathrm{LFO}_{2}-72\right.$ vs $50 \%, p<0.01$; HFNO -47 vs $24 \%, p<0.01$ and NPPV -38 vs $28 \%, p=0.20)$. The proportion of respondents who reported that $\mathrm{LFO}_{2}$ was either not an option at all or unwilling to use $\mathrm{LFO}_{2}$ in neutral pressure rooms increased from $54 \%$ in phase 1 to $73 \%$ in phase 2; $p=0.02$. Correspondingly, the proportion of those who were unwilling to use HFNO in neutral-pressure rooms also reduced from 32 to $23 \%$ $(p=0.20)$. Only $25 \%$ of respondents were comfortable in managing NPPV in neutral-pressure rooms, which reduced from 29 to $23 \%$ from phase 1 to phase $2(p=1.00)$. Figure $2 \mathrm{~B}$ demonstrated that the respondents had a negative trend in comfort levels with the increasing complexity of oxygenation therapies in neutral-pressure rooms.

\section{Discussion}

This survey identified interesting results that are relevant in managing non-intubated COVID-19 patients with hypoxemic respiratory failure. Regarding the mode of oxygen therapy, fewer clinicians seemed comfortable in using HFNO/NPPV compared to $\mathrm{LFO}_{2}$. Regarding the location of managing non-intubated COVID19 patients, fewer clinicians were comfortable to offer any form of noninvasive oxygen therapy in neutral-pressure rooms (including $\mathrm{LFO}_{2}$ ), especially in phase 2 . This tendency was significantly higher in private hospitals compared to first-responder hospitals.

These results assume relevance in the setting of controversies and concerns of SARS-CoV-2 being transmitted as aerosols. ${ }^{21-23}$ Recently, 239 scientists from 32 countries wrote an open letter urging the World Health Organization (WHO) and other bodies to address the potential for airborne transmission of the coronavirus. ${ }^{21}$ In response, the WHO has reaffirmed its original position that although SARS-CoV-2 transmission occurs primarily through contact or droplets, the airborne transmission may occur with aerosol-generating procedures in healthcare settings. ${ }^{23}$ Therefore,

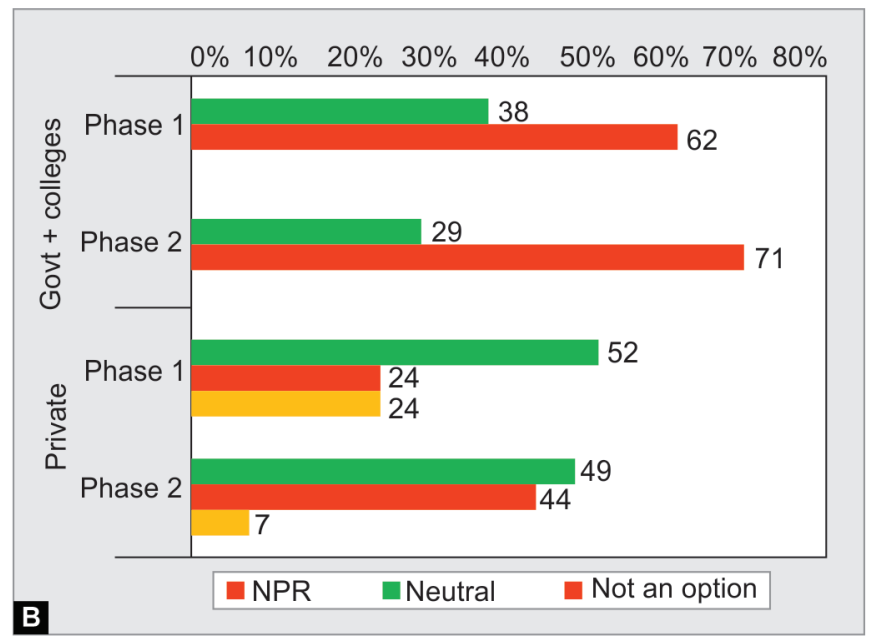

Figs $1 \mathrm{~A}$ and B: Proposed location to treat confirmed COVID patients requiring ICU admission: (A) Comfort levels of doctors with different noninvasive oxygenation therapies based on NPR, neutral pressure room and not an option* for the two phases; (B) Represents distribution based on the type of institution (First-responder** and Private Hospitals) based on phases 1 and 2 refer Supplementary Figure 1 for the statewide distribution and variation among them (presented as actual numbers). NPR, negative pressure room. *Not an option-implies that there is no role for the type of oxygenation therapy and patients intubated early; **First-Responder Hospitals_Government Hospitals and Medical College Hospitals 

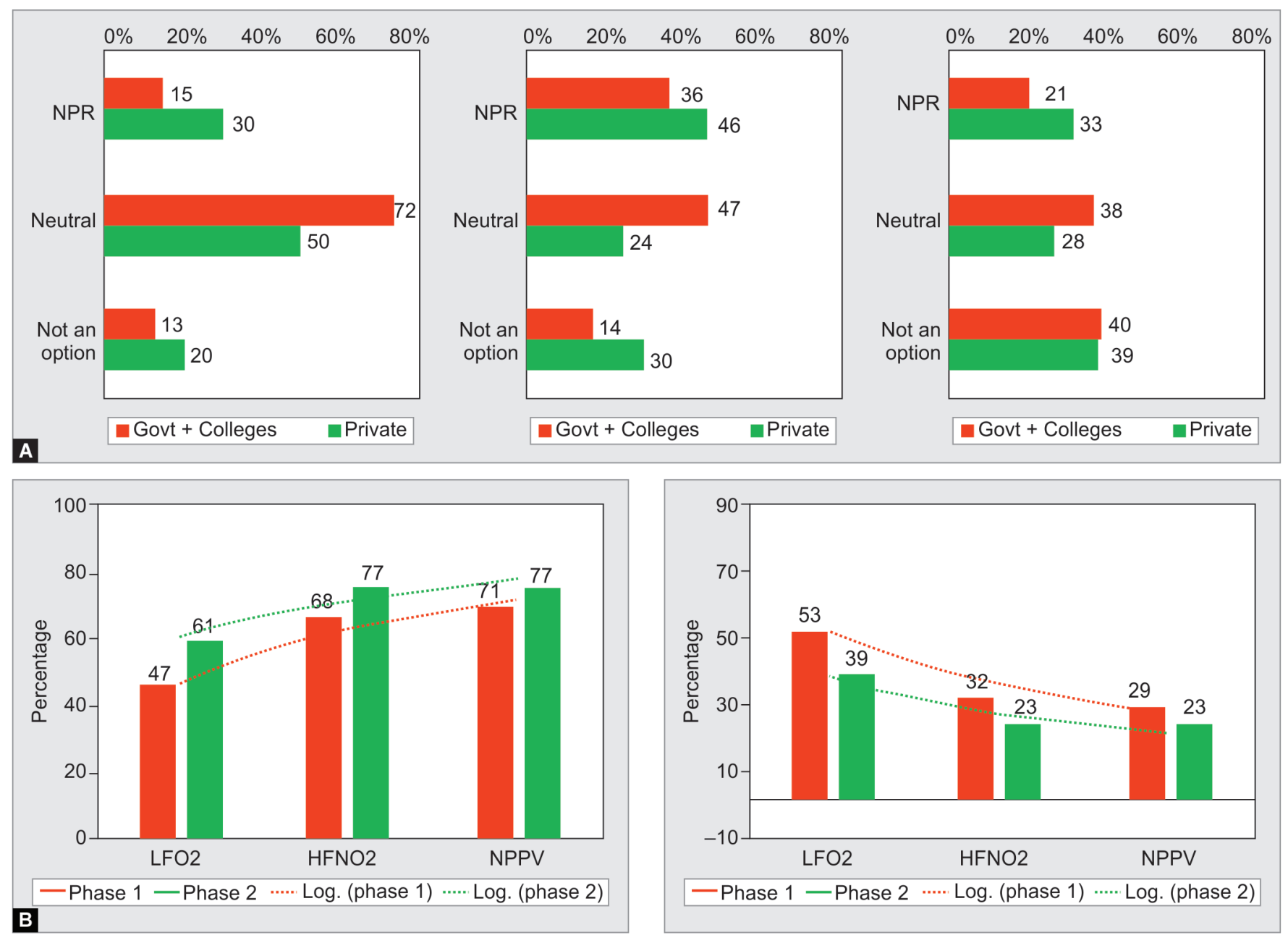

Figs 2A and B: Oxygenation management preferences: (A) The respondents' comfort levels for different noninvasive oxygenation therapies based on the type of hospitals they worked; (B) The proportion of respondents' discomfort logarithmically dropped, more so in phase 2 with the increasing complexity of oxygenation therapies in neutral pressure room in the two phases. NPR, negative pressure room. ${ }^{*}$ First-Responder Hospitals-Government Hospitals and Medical College Hospitals

the choice of noninvasive oxygen therapies and/or patient cohorts may directly impact HCW-infection risk.

In India, concerns from the early phase of the pandemic, namely shortages of hospital beds, personal protective equipment (PPE), and ventilators may have been addressed by the creation of new COVID-19 hospitals and increased domestic manufacturing of PPE ${ }^{24}$ and ventilators. ${ }^{25}$ However, there may still be a lack of negativepressure rooms and skilled personnel for complex COVID-19 ICU management. Therefore, noninvasive oxygen therapies may have an important role, provided ICUs employ safe PPE practice and engineering solutions as outlined in a comprehensive position statement by the Indian Society of Critical Care Medicine (ISCCM). ${ }^{26}$ We urge that all ICUs, both existing and new makeshift hospitals/ ICUs follow the principles outlined in that statement. ${ }^{27,28}$ The variation in practices among different states and private vs firstresponders may reflect differential resource availability. This may need resolution at national, state, and local levels.

To the best of our knowledge, this study was the first to evaluate the oxygen-therapy practices in Indian ICUs for COVID-19 patients. It reflects the opinions of senior clinicians in a decision-making capacity with a good geographical spread across India. It was done in two time periods, from the early phase of the pandemic and also during the initial surge. The use of a case vignette made the question clinically relevant.

We acknowledge the following limitations. Given that the study was conducted in late March to April, the opinions of the respondents may have further evolved over time. Currently, India is stage 3 with community transmission. However, when this survey was performed, India was still in stage 2 . Inherent to any surveys, there may be a likely bias among the sample of respondents. In addition, we did not evaluate other emerging therapies for nonintubated patients, such as, the use of non-rebreathing masks, ${ }^{29}$ helmet NPPV masks, ${ }^{30}$ ICU-bed ventilation hoods, ${ }^{8,31}$ or adopting awake self-prone positioning. ${ }^{32-36}$

\section{Conclusion}

In the setting of controversies surrounding SARS-CoV-2 transmission, this survey of Indian intensivists/anesthetists from 24 states demonstrated that doctors predominantly preferred managing noninvasive oxygen therapies in negative-pressure rooms. There was variability in the location of proposed therapy between private hospitals and first-responder hospitals. Since societal guidelines 
advocate a role for noninvasive oxygen therapy in managing the early stages of COVID-19 pneumonia, while rigorously conforming to the ISCCM position statement on safe PPE practice, while more data on the spread of COVD-19 pneumonia emerges.

\section{References}

1. Coronavirus disease (COVID-19) - Situation Report \#155. World Health Organisation, 2020. (Accessed June 24th 2020, 2020, at Coronavirus disease (COVID-19).).

2. Phua J, Weng L, Ling L, Egi M, Lim PC-M, Divatia JV, et al. Intensive care management of coronavirus disease 2019 (COVID-19): challenges and recommendations. Lancet Respir Med 2020;8(5):506-517. DOI: 10.1016/S2213-2600(20)30161-2.

3. Chawla R, Dixit SB, Zirpe KG, Chaudhry D, Khilnani GC, Mehta Y, et al. ISCCM guidelines for the use of non-invasive ventilation in acute respiratory failure in adult ICUs. Indian J Crit Care Med 2020;24:S61s81.

4. Onder G, Rezza G, Brusaferro S. Case-fatality rate and characteristics of patients dying in relation to COVID-19 in Italy. JAMA 2020;323(18):17751776. DOI: 10.1001/jama.2020.4683.

5. Pivoting Critical Care Research to Help with the COVID-19 Pandemic. Newswise, 2020. (Accessed June 24th 2020, at https://www.newswise. com/coronavirus/pivoting-critical-care-research-to-help-with-thecovid-19-pandemic/?article_id=730343.).

6. Leung $\mathrm{CCH}$, Joynt $\mathrm{GM}$, Gomersall CD, Wong WT, Lee $A$, Ling $L$, et al. Comparison of high-flow nasal cannula versus oxygen face mask for environmental bacterial contamination in critically ill pneumonia patients: a randomized controlled crossover trial. J Hosp Infect 2019;101(1):84-87. DOI: 10.1016/j.jhin.2018.10.007.

7. Loh NHW, Tan Y, Taculod J, Gorospe B, Teope AS, Somani J, et al. The impact of high-flow nasal cannula (HFNC) on coughing distance: implications on its use during the novel coronavirus disease outbreak. Can J Anaesth 2020;67(7):893-894. DOI: 10.1007/s12630-020-01634-3.

8. McGain F, Humphries RS, Lee JH, Schofield R, French C, Keywood MD, et al. Aerosol generation related to respiratory interventions and the effectiveness of a personal ventilation hood. Crit Care Resusc 2020. Online ahead of print.

9. Iwashyna TJ, Boehman A, Capelcelatro J, Cohn AM, Cooke JM, Costa DK, et al. Variation in aerosol production across oxygen delivery devices in spontaneously breathing human subjects. medRxiv 2020. DOI: 2020.04.15.20066688.

10. Li J, Fink JB, Ehrmann S. High-flow nasal cannula for COVID-19 patients: low risk of bio-aerosol dispersion. Eur Respir J 2020;55(5):2000892. DOI: 10.1183/13993003.00892-2020.

11. ANZICS COVID-19 Guidelines. Australian and New Zealand Intensive Care Society (ANZICS), 2020. (Accessed March 31 2020, 2020, at https:// www.anzics.com.au/wp-content/uploads/2020/03/ANZICS-COVID19-Guidelines-Version-1.pdf.).

12. Kluge $S$, Janssens $U$, Welte $T$, Weber-Carstens $S$, Marx $G$, Karagiannidis C. German recommendations for critically ill patients with COVID-19. Medizinische Klinik, Intensivmedizin und Notfallmedizin 2020. 1-4. DOI: 10.1007/s00063-020-00689-w.

13. Effectiveness of different forms of oxygen therapy for COVID-19 management. World Health Organization, 2020. (Accessed June 15, 2020, at https://apps.who.int/iris/bitstream/handle/10665/332305/ WHO-AF-ARD-DAK-04-2020-eng.pdf?sequence=3\&isAllowed=y.).

14. Kumar P, Kumar M. Management of potential ventilator shortage in India in view of on-going COVID-19 pandemic. Indian J Anaesth 2020;64(14):151-152. DOI: 10.4103/ija.IJA_342_20.

15. Ozair A, Agrawal A, Siddiqui SS. Training and delivery of critical care medicine in India: concerns revealed by COVID-19 pandemic. Indian J Crit Care Med 2020;24(4):285-286. DOI: 10.5005/ jp-journals-10071-23404.

16. Pandey T. No need to clap, but don't shut our voices: Doctors flag backlash for speaking out. India Today 2020 07/04/2020.

17. Murthy PR, Gupta KV, Ajith Kumar AK. Is anxiety a rising concern during COVID-19 pandemic among healthcare workers? Indian J Crit Care Med 2020;24(5):369-370. DOI: 10.5005/jp-journals-10071-23434.
18. Rajamani A, Subramaniam A, Shekar K, Haji J, Luo J, Bihari S, et al. On behalf of the SPARTAN collaborative - small projects, audits, research trials - Australia/New Zealand, personal protective equipment preparedness in Asia-Pacific intensive care units during the COVID19 pandemic: A multinational survey, Australian critical care. DOI: 10.1016/j.aucc.2020.09.006.

19. Haji JY, Subramaniam A, Kumar P, Ramanathan K, Rajamani A. The state of personal protective equipment practice in Indian intensive care units amidst COVID-19 pandemic: A nationwide survey. Indian J Crit Care Med 2020;24(9):809-816.

20. Thacker TSN, Covid-19 in India: Cautious government involves private sector in treating patients. Economic Times 2020.

21. Morawska L, Milton DK. It is time to address airborne transmission of COVID-19. Clin Infect Dis 2020. ciaa939. DOI: 10.1093/cid/ ciaa939.

22. World Health Organization. Modes of transmission of virus causing COVID-19: implications for IPC precaution recommendations: scientific brief, 29 March 2020. Geneva: World Health Organization; 2020.

23. Transmission of SARS-CoV-2: implications for infection prevention precautions. 2020. (Accessed July 11th, 2020, at https://www.who. int/news-room/commentaries/detail/transmission-of-sars-cov-2implications-for-infection-prevention-precautions.).

24. PTI. India becomes world's second largest manufacturer of PPE bod. Read more at: http://timesofindia.indiatimes.com/ articleshow/75871010.cms?utm_source=contentofinterest\&utm_ medium=text\&utm_campaign=cppst. Times of India 2020 May 21.

25. Sarin R, As Covid curve rises, surge in ventilators causes glut. The Indian Express 2020.

26. Mehta Y, Chaudhry D, Abraham OC, Chacko J, Divatia J, Jagiasi B, et al. Critical care for COVID-19 affected patients: position statement of the Indian Society of Critical Care Medicine. Indian J Crit Care Med 2020;24(4):222-241. DOI: 10.5005/jp-journals-10071-23395.

27. Jumbo SJ. NSCI Dome facility set to turn into COVID-19 hospital. The Hindu 2020 May 25th 2020.

28. Aljazeera, Delhi opens makeshift 10,000-bbed hospital amid coronavirus surge. Aljazeera 2020 July 2nd 2020.

29. Kumar A, Kumar A, Kumar N, Kumar A, Singh PK. Modified oxygen therapy device for prevention of aerosol dispersion in COVID-19 patients. J Clin Anesth 2020;65:109884. DOI: 10.1016/j. jclinane.2020.109884.

30. Ing RJ, Bills C, Merritt G, Ragusa R, Bremner RM, Bellia F. Role of helmet-delivered noninvasive pressure support ventilation in COVID19 patients. J Cardiothorac Vasc Anesth 2020;34(10):2575-2579. DOI: 10.1053/j.jvca.2020.04.060.

31. Prendergast K. Ventilation hoods for ICU beds to protect healthcare workers. Nursing Review 2020 17/04/2020.

32. Caputo ND, Strayer RJ, Levitan R. Early self-proning in awake, non-intubated patients in the emergency department: a single ED's experience during the COVID-19 pandemic. Acad Emerg Med 2020;27(5):375-378. DOI: 10.1111/acem.13994.

33. Coppo A, Bellani G, Winterton D, Di Pierro M, Soria A, Faverio P, et al. Feasibility and physiological effects of prone positioning in nonintubated patients with acute respiratory failure due to COVID-19 (PRON-COVID): a prospective cohort study. Lancet Respir Med 2020;8(8):P765-P774. DOI: 10.1016/S2213-2600(20)30268-X.

34. Ding L, Wang L, Ma W, He H. Efficacy and safety of early prone positioning combined with HFNC or NIV in moderate to severe ARDS: a multi-center prospective cohort study. Crit Care 2020;24(1):28. DOI: 10.1186/s13054-020-2738-5.

35. Elharrar X, Trigui Y, Dols AM, Touchon F, Martinez S, Prud'homme E, et al. Use of prone positioning in nonintubated patients with COVID-19 and hypoxemic acute respiratory failure. JAMA 2020;323(22):23362338. DOI: 10.1001/jama.2020.8255.

36. Jiang LG, LeBaron J, Bodnar D, Caputo ND, Chang BP, Chiricolo G, et al. Conscious proning: an introduction of a proning protocol for nonintubated, awake, hypoxic emergency department COVID19 patients. Acad Emerg Med 2020;27(7):566-569. DOI: 10.1111/ acem.14035. 
1 Supplementary Figure 1: The 2 questions in the Survey, discussed in this manuscript.

What is the proposed location to treat confirmed COVID patients requiring ICU admission? *

More than one answer may be chosen

Check all that apply.

$\square$ Negative pressure-room

$\square$ Negative flow room

$\square$ Neutral pressure single room in a general pod with other non-COVID patients

$\square$ Cohorted with other COVID patients in a dedicated COVID pod

2 Other:

A young well-functioning patient has confirmed COVID. His resp rate is 30/min with Sats $\sim 80-85 \%$ on room air. Other systems are normal. What $\mathrm{O} 2$ therapy is considered appropriate in your hospital? *

More than one answer may be chosen

Check all that apply.

\begin{tabular}{|c|c|c|c|c|}
\hline & $\begin{array}{l}\text { Not an } \\
\text { option } \\
\text { in } \\
\text { COVID }\end{array}$ & $\begin{array}{c}\text { In } \\
\text { negative } \\
\text { pressure } \\
\text { room }\end{array}$ & $\begin{array}{l}\text { Neutral- } \\
\text { pressure } \\
\text { single } \\
\text { room }\end{array}$ & $\begin{array}{l}\text { Ward or } \\
\text { Dedicated } \\
\text { ICU pod } \\
\text { of } \\
\text { cohorted } \\
\text { COVID } \\
\text { patients }\end{array}$ \\
\hline $\begin{array}{l}\text { Low } \\
\text { flow } \\
\text { nasal } \\
\text { prongs } \\
\text { (<6 } \\
\text { L/min) }\end{array}$ & 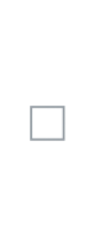 & 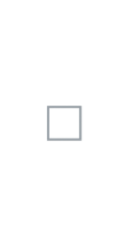 & 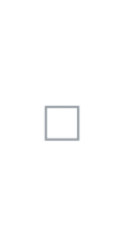 & \begin{tabular}{|l|} 
\\
\end{tabular} \\
\hline $\begin{array}{l}\text { High- } \\
\text { flow } \\
\text { nasal } \\
\text { prongs }\end{array}$ & 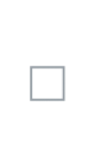 & $\square$ & \begin{tabular}{|l} 
\\
\end{tabular} & $\square$ \\
\hline CPAP & $\square$ & $\square$ & $\square$ & $\square$ \\
\hline
\end{tabular}




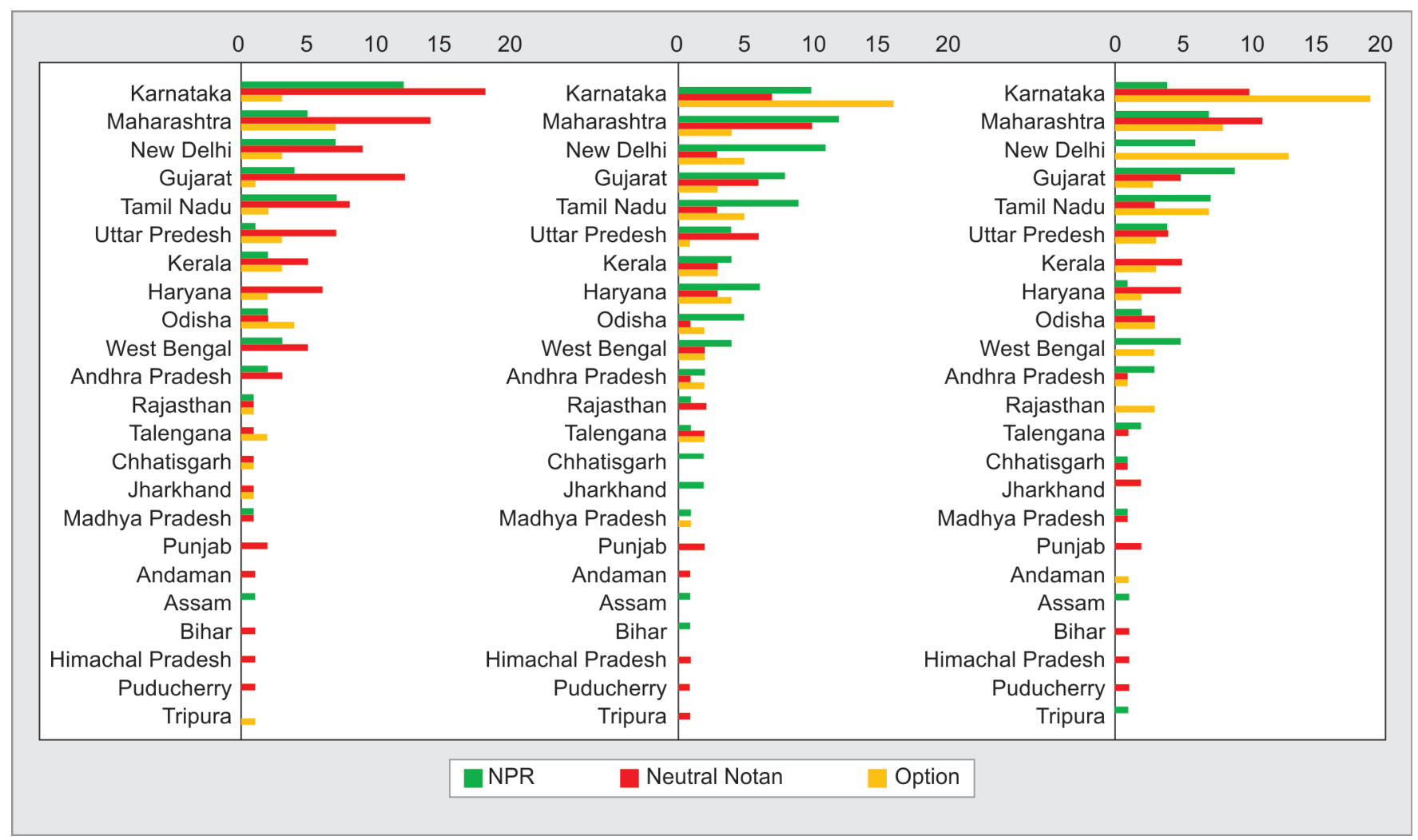

Supplementary Fig. 2: Variation in comfort levels of intensivists/anesthetists from different states and territories in using noninvasive oxygenation therapies in managing the patient described in the clinical vignette 